2 Craig RG, Hunter JM. Recent developments in the perioperative management of adult patients with chronic kidney disease. Br J Anaesth 2008;101(3):296-310

3 Chen S, Li Q, Wu H, Krafft PR, Wang Z, Zhang JH. The harmful effects of subarachnoid hemorrhage on extracerebral organs. BioMed Res Int 2014;2014:858-496

4 Rang ST, West NL, Howard J, Cousins J. Anaesthesia for chronic renal disease and renal transplantation. EAU-EBU Update Ser 2006;4:246-256

5 Rudnick MR, Goldfarb S, Wexler L, et al. Nephrotoxicity of ionic and nonionic contrast media in 1196 patients: a randomized trial. The Iohexol Cooperative Study. Kidney Int 1995;47(1):254-261

6 Katzberg RW, Newhouse JH. Intravenous contrast medium-induced nephrotoxicity: is the medical risk really as great as we have come to believe. ? Radiology 2010;256(1):21-28

7 Mitra R, Rath GP, Dube SK, Hasija N. Anesthetic management in a patient of autosomal dominant polycystic kidney disease with end stage renal disease undergoing endovascular coiling for multiple intracranial aneurysms. J Anaesthesiol Clin Pharmacol 2017;33(2):256-258

8 Aspelin P, Aubry P, Fransson SG, Strasser R, Willenbrock R, Berg KJ; Nephrotoxicity in High-Risk Patients Study of IsoOsmolar and Low-Osmolar Non-Ionic Contrast Media Study Investigators. Nephrotoxic effects in high-risk patients undergoing angiography. N Engl J Med 2003;348(6):491-499

9 Owen RJ, Hiremath S, Myers A, Fraser-Hill M, Barrett BJ. Canadian Association of Radiologists consensus guidelines for the prevention of contrast-induced nephropathy: update 2012. Can Assoc Radiol J 2014;65(2):96-105

10 Freeman RV, O’Donnell M, Share D, et al; Blue Cross-Blue Shield of Michigan Cardiovascular Consortium (BMC2). Nephropathy requiring dialysis after percutaneous coronary intervention and the critical role of an adjusted contrast dose. Am J Cardiol 2002;90(10):1068-1073

\title{
Inherited Factor XII Deficiency-What Is the Real Concern for Neuroanesthesiologist: Bleeding or Clotting
}

\author{
Mouleeswaran Sundaram $^{1}$ Sonia Bansal ${ }^{1}$ Rohini M. Surve ${ }^{1}$ \\ ${ }^{1}$ Department of Neuroanaesthesia and Neurocritical Care, \\ National Institute of Mental Health and Neurosciences, \\ Bengaluru, Karnataka, India

\begin{abstract}
Address for correspondence Sonia Bansal, MD, DNB, PDF, Department of Neuroanesthesia and Neurocritical Care, National Institute of Mental Health and Neurosciences, 3rd Floor, Faculty Block, Neurocentre, Bengaluru 560029, Karnataka, India (e-mail: itz.sonia77@gmail.com).
\end{abstract}

J Neuroanaesthesiol Crit Care 2021;8:210-212.

\begin{abstract}
Keywords

- factor XII

- surgery

- bleeding

- thromboembolism

Factor XII deficiency is a rare disorder that can complicate the perioperative management of a patient. Factor XII plays an important role in the activation of intrinsic pathway of coagulation; the deficiency, therefore, results in prolongation of activated partial thromboplastin time (aPTT). This aPTT prolongation is expected to cause increased bleeding during surgery. However, on the contrary, in vivo isolated factor XII deficiency is associated with increased risk of thromboembolism (this risk being higher than the risk of bleeding). We report the perioperative management of a patient with factor XII deficiency who underwent cervical vertebral fusion $\left(C_{1}-C_{2}\right)$ for atlantoaxial dislocation.
\end{abstract}

published online

June 11,2020
DOI https://doi.org/

$10.1055 / \mathrm{s}-0040-1713559$

ISSN 2348-0548. (c) 2020. Indian Society of Neuroanaesthesiology and Critical Care.

This is an open access article published by Thieme under the terms of the Creative Commons Attribution-NonDerivative-NonCommercial-License, permitting copying and reproduction so long as the original work is given appropriate credit. Contents may not be used for commercial purposes, or adapted, remixed, transformed or built upon. (https://creativecommons.org/licenses/by-nc-nd/4.0/).

Thieme Medical and Scientific Publishers Pvt. Ltd. A-12, 2nd Floor, Sector 2, Noida-201301 UP, India 


\section{Introduction}

Inherited bleeding and clotting disorders can complicate the intraoperative anesthetic management especially in neurosurgical procedures where significant amount of blood loss is expected. Perioperative management of patients with these disorders remains a challenge to the neuroanesthesiologist. Of all these disorders, factor XII deficiency is extremely rare and is usually diagnosed incidentally when a prolonged activated partial thromboplastin time (aPTT) is observed during preoperative evaluation. We report the perioperative management of a patient with factor XII deficiency who underwent cervical vertebral fusion $\left(C_{1}-C_{2}\right)$ for atlantoaxial dislocation (AAD).

\section{Case Report}

A 38-year-old male, weighing $38 \mathrm{~kg}$ and height of $160 \mathrm{~cm}$, presented with increasing neck pain with tingling and numbness of both upper limbs. The patient was moderately built and had pallor. The muscle power was $3 / 5$ at the right wrist and $4 / 5$ at the left wrist joint. Airway examination showed restricted mouth opening ( $<1$ finger breadth) and a Modified Mallampatti Class IV. Echocardiography was normal and the pulmonary function tests showed moderate restrictive lung disease. After magnetic resonance imaging, a diagnosis of ankylosing spondylitis with AAD was made. He was planned for posterior fusion of $C_{1}-C_{2}$ with lateral mass screws.

During evaluation, hemoglobin ( $\mathrm{Hb})$ of $7.3 \mathrm{~g} / \mathrm{dL}$ and a prolonged aPTT value (73 seconds) with a normal platelet count (4.12 lakhs/cu mm) and prothrombin time (12.8 seconds) was observed. The test was repeated twice and consecutive values were high. Patient denied any history of prolonged bleeding after injury. Hematologist diagnosed him with anemia and reduced levels of factor XII (18 IU/mL, normal value-50 IU/ $\mathrm{mL}$ ). Factor VIII, factor IX, protein C and S assays were normal. Mixing studies were performed to rule out the presence of factor XII inhibitors. Mixing patient's plasma and test plasma in the ratio of $1: 1$ led to shortening of aPTT indicating the absence of factor XII inhibitors. Therefore, aPTT prolongation was due to deficiency of factor XII. The patient was started on hematinics and a follow-up was planned after 2 weeks.

On re-evaluation, the reduction in factor XII levels (28.9 IU/mL) and mild prolongation of aPTT (44 seconds) persisted and $\mathrm{Hb}$ improved to $8.2 \mathrm{~g} / \mathrm{dL}$. Literature search revealed that there were no guidelines with respect to the range at which correction of aPTT is recommended in factor XII deficiency. ${ }^{1}$ Also, there is no consensus for minimum desired factor XII level for hemostasis in vivo. ${ }^{1}$ Hence, surgery was scheduled.

Adequate blood and blood products were reserved. Patient was counseled about the nature of the condition, expected complications, and informed consent was taken. We did not transfuse fresh frozen plasma (FFP) preoperatively and plan was to transfuse, based on intraoperative blood loss, to avoid unnecessary complications of blood product administration. Awake orotracheal fiberoptic intubation was performed. Anesthesia was thereafter induced; adequate venous access and invasive arterial line were secured. An intermittent pneumatic compression device (IPCD) was placed to prevent venous thrombosis. A close watch was maintained for abnormal bleeding. However, no abnormal bleeding occurred and surgery lasted 9 hours. A total blood loss of $500 \mathrm{~mL}$ occurred that was replaced with two units of packed red blood cells and $\mathrm{Hb}$ was $8.6 \mathrm{~g} / \mathrm{dL}$ at the end of surgery. After reversal of neuromuscular blockade, motor power was $4 / 5$ in both upper limbs and 5/5 bilaterally in the lower limbs. Patient was not extubated in view of difficult airway, nature of surgery, and prolonged procedure time and was shifted to intensive care unit. Patient was extubated the next day, mobilised and started on enoxaparin $60 \mathrm{mg}$ subcutaneously once a day with daily screening for occurrence of deep venous thrombosis (DVT). The postoperative course was uneventful and patient was discharged on 5 th postoperative day.

\section{Discussion}

Factor XII also known as Hageman factor is synthesized in the liver. It is a single chain glycoprotein with molecular weight of 80,000 daltons, half-life of 60 hours, and normal plasma concentration of $50 \mathrm{IU} / \mathrm{mL}(30 \mu \mathrm{g} / \mathrm{mL}) .{ }^{1}$ Factor XII deficiency can be both inherited (autosomal recessive) and acquired. Acquired causes include nephrotic syndrome, sepsis, and disseminated intravascular coagulation. The overall prevalence of the disorder is $\sim 1.5$ to $3.0 \%$, with severe factor XII deficiency (activity $<1 \%$ ) in a minority. ${ }^{2}$

Factor XII deficiency is one of the causes for prolongation of aPTT. Other causes of prolonged aPTT include deficiency of coagulation factors VIII, IX, X, XI, V, or II; deficiency of factors for contact phase activation; Von Willebrand disease, liver disease, vitamin K deficiency; therapeutic anticoagulation; and autoimmune diseases (due to anti-phospholipid antibodies). Whenever isolated prolongation of aPTT is encountered, management involves identification of the cause (with specific assays) and correcting it, administration of recombinant clotting factors, factor concentrates, FFP, or cryoprecipitate as per the clinical manifestations. ${ }^{3}$

Factor XII, prekallikrein, and high-molecular-weight kininogen are important for activation of contact phase of coagulation. Factor XII is activated by plasma kallikrein during endothelial injury. Activated factor XII is the first component of intrinsic pathway of coagulation. Also, fragments of factor XII activate plasminogen during the initiation of normal fibrinolysis. Therefore, factor XII deficiency affects coagulation as well as fibrinolysis.

In our patient, the activity of factor XII was $31 \%$ of mean normal range with mild prolongation of aPTT. In patients with severe factor XII deficiency, aPTT values may exceed 120 seconds. Unlike previous literature reports, we did not transfuse FFP for normalization of aPTT. ${ }^{4}$ This is justified by the fact that although factor XII plays an important role in activation of coagulation cascade in vitro, its role is very negligible in in vivo coagulation activation and extrinsic pathway is sufficient for activation of coagulation pathway in humans. ${ }^{1}$ Thus, even severe form of isolated factor XII deficiency does not cause hemostatic problems perioperatively, and prophylactic transfusion with $\mathrm{FFP} /$ cryoprecipitate is not warranted. This also explains why there was no abnormal bleeding intraoperatively in our patient. However, the factor XII levels were not very low and there was only a mild prolongation of aPTT in our case. 
Factor XII deficiency inhibits fibrinolysis and therefore can lead to thromboembolic complications. ${ }^{5}$ Patients with isolated factor XII deficiency have a high rate of venous thromboembolism and arterial thrombosis, leading to life threatening complications such as pulmonary embolism and myocardial infarction. ${ }^{6}$ In addition, surgical trauma and immobilization increase the risk of thromboembolic complications. This necessitates the use of thromboprophylaxis perioperatively (mechanical and pharmacological) and early aggressive mobilization postoperatively. ${ }^{7}$ We used IPCD intraoperatively and in the postoperative period, low molecular weight heparin, early mobilization, and daily screening for DVT was done in addition to continued use of IPCD.

In conclusion, patients with factor XII deficiency are at high risk of thromboembolism for which vigilant monitoring and measures for thromboprophylaxis should be undertaken perioperatively. The risk of bleeding, although present, is not so alarming. The prophylactic correction of prolonged aPTT should be given a second thought.

Conflict of Interest

None declared.

\section{References}

1 Kessler C, Coagulation factor deficiencies. In: Goldman L, ed. Cecil Textbook of Medicine. Twenty-first edition. Philadelphia, USA: Saunders Company; 2000 1004-1012

2 Halbmayer WM, Haushofer A, Schön R, et al. The prevalence of moderate and severe FXII (Hageman factor) deficiency among the normal population: evaluation of the incidence of FXII deficiency among 300 healthy blood donors. Thromb Haemost 1994;71(1):68-72

3 Barbosa ACN, Montalvão SAL, Barbosa KGN, et al. Prolonged APTT of unknown etiology: a systematic evaluation of causes and laboratory resource use in an outpatient hemostasis academic unit. Res Pract Thromb Haemost 2019;3(4):749-757

4 Dragoumanis C, Vretzakis G, Vogiatzaki T. Perioperative management of a patient with severe factor XII deficiency. Eur J Anaesthesiol 2004;21(10):829-830

5 Pauer HU, Burfeind P, Köstering H, Emons G, Hinney B. Factor XII deficiency is strongly associated with primary recurrent abortions. Fertil Steril 2003;80(3):590-594

6 Chaudhry LA, El-Sadek WYM, Chaudhry GA, Al-Atawi FE. Factor XII (Hageman Factor) deficiency: a rare harbinger of life threatening complications. Pan Afr Med J 2019;33:39

7 Bick RL, Haas S. Thromboprophylaxis and thrombosis in medical, surgical, trauma, and obstetric/gynecologic patients. Hematol Oncol Clin North Am 2003;17(1):217-258

\title{
Dilated Cardiomyopathy and Prone Position: An Anesthetic Challenge
}

\author{
Bhavna Hooda ${ }^{1}$ Saurabh Sud ${ }^{1, \oplus}$ Deepak Dwivedi ${ }^{1}$ \\ ${ }^{1}$ Department of Anaesthesia and Critical Care, Command Hospital \\ (Southern Command), Pune, Maharashtra, India \\ 2Department of Neurosurgery, Command Hospital (Southern \\ Command), Pune, Maharashtra, India
}

Sanjay K. Yadav

\begin{abstract}
Address for correspondence Saurabh Sud, MD (Anaesthesia), Department of Anaesthesia and Critical Care, Command Hospital (Southern Command), Pune 411040, Maharashtra, India (e-mail: saurabhsood1975@gmail.com).
\end{abstract}

J Neuroanaesthesiol Crit Care 2021;8:212-214.
Abstract
Keywords
- cardiac resynchronization therapy device
- dilated cardiomyopathy
- prone position

The anesthetic management of a patient with dilated cardiomyopathy (DCM) for noncardiac surgery is challenging due to associated congestive heart failure, malignant dysrhythmias, sudden cardiac arrest, implanted rhythm devices, and thromboembolism. We report successful conduct of a case of DCM on cardiac resynchronization device with Cauda equina syndrome (CES) under general anesthesia in prone position. The anesthetic concerns specific to the pathophysiology of DCM are also discussed. published online June 30,2020
DOI https://doi.org/

$10.1055 / \mathrm{s}-0040-1713726$ ISSN 2348-0548. (c) 2020. Indian Society of Neuroanaesthesiology and Critical Care. This is an open access article published by Thieme under the terms of the Creative Commons Attribution-NonDerivative-NonCommercial-License, permitting copying and reproduction so long as the original work is given appropriate credit. Contents may not be used for commercial purposes, or adapted, remixed, transformed or built upon. (https://creativecommons.org/licenses/by-nc-nd/4.0/).

Thieme Medical and Scientific Publishers Pvt. Ltd. A-12, 2nd Floor, Sector 2, Noida-201301 UP, India 